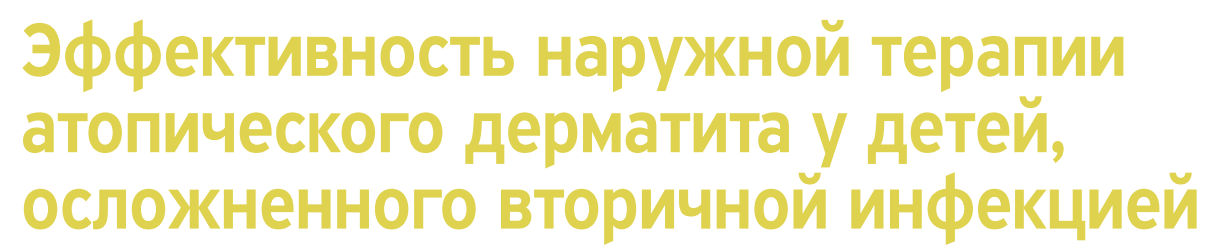

Т.Г. Маланичева, https://orcid.org/0000-0002-7027-0319, tgmal@mail.ru

Н.В. Зиатдинова ${ }^{\bowtie}$, https://orcid.org/0000-0002-4296-1198, ziatdin@mail.ru

Казанский государственный медицинский университет; 420012, Россия, Казань, ул. Бутлерова, д. 49

\title{
Резюме
}

Введение. В современных условиях атопический дерматит характеризуется ранним началом, упорным рецидивирующим течением, развитием осложнений и имеет определенные трудности в лечении. В настоящее время в условиях экологического неблагополучия, нерационального применения антибиотиков одним из факторов, приводящих к утяжелению атопического дерматита, является бактериальная и грибковая инфекция, которая играет важную роль в поддержании хронического воспалительного процесса в коже.

Цель. Усовершенствовать методы лечения атопического дерматита у детей, осложненного грибковой и бактериальной инфекцией, с использованием нестероидного препарата активированного пиритиона цинка (в форме крема 0,2\% или аэрозоля 0,2\%), оказывающего противомикробное и противогрибковое, а также противовоспалительное действие.

Материалы и методы. Под наблюдением находилось 46 детей в возрасте от 1 до 3 лет с осложненными формами атопического дерматита. Наружно применялся препарат активированного пиритиона цинка в составе комплексной противоаллергической терапии.

Результаты и обсуждение. На фоне проводимой терапии отмечался положительный клинический эффект в 69,5\% случаев и достижение стойкой ремиссии заболевания в среднем на 16-й день от начала терапии. Результаты культурального бактериологического и микологического обследования были отрицательными в 78,1\% случаев. Динамическое наблюдение за детьми в течение 1 года показало, что у 53,1\% наблюдалась стойкая ремиссия заболевания, а у 28,1\% детей обострения, отмечаемые после проводимого лечения, характеризовались более низкой интенсивностью клинических проявлений.

Выводы. Включение в состав комплексного лечения атопического дерматита, осложненного вторичной грибковой и бактериальной инфекцией, нестероидного препарата активированного пиритиона цинка (в форме крема 0,2\% или аэрозоля 0,2\%) в варианте топической монотерапии показало высокую клиническую эффективность.

Ключевые слова: атопический дерматит, дети, вторичная грибковая и бактериальная инфекция, наружная терапия, активированный пиритион цинк

Для цитирования: Маланичева Т.Г., Зиатдинова Н.В. Эффективность наружной терапии атопического дерматита у детей, осложненного вторичной инфекцией. Медицинский совет. 2022;16(1):150-152. https://doi.org/10.21518/2079-

701X-2022-16-1-150-152.

Конфликт интересов: авторы заявляют об отсутствии конфликта интересов.

\section{Effectiveness of topical therapy of secondarily infected atopic dermatitis in children}

Tatyana G. Malanicheva, https://orcid.org/0000-0002-7027-0319, tgmal@mail.ru Nelli V. Ziatdinova ${ }^{\bowtie}$, https://orcid.org/0000-0002-4296-1198, ziatdin@mail.ru

Kazan State Medical University; 49, Butlerov St., Kazan, 420012, Russia

\section{Abstract}

Introduction. In present day conditions, atopic dermatitis is characterized by an early onset, persistent relapsing course, development of complications and has certain difficulties in treatment. Nowadays, in unfavourable environmental context and irrational use of antibiotics, bacterial and fungal infection is one of the factors leading to the aggravation of atopic dermatitis, which plays an important role in maintaining a chronic inflammatory process in the skin.

Aim. To improve methods for treating atopic dermatitis complicated by fungal and bacterial infection in children by using non-steroidal activated zinc pyrithione drug (in the form of $0.2 \%$ cream or $0.2 \%$ aerosol), which has antimicrobial and antifungal, as well as anti-inflammatory effects.

Materials and methods. 46 children aged 1 to 3 years with complicated forms of atopic dermatitis were observed. They used activated zinc pyrithione drug applied topically as part of the complex antiallergic therapy.

Results and discussion. The on-going therapy resulted in a positive clinical effect in $69.5 \%$ of cases and the achievement of a stable remission of the disease on average on the 16th day from the start of therapy. The results of cultural bacteriological and mycological examination were negative in $78.1 \%$ of cases. The one-year dynamic follow-up of children showed that $53.1 \%$ had 
a stable remission of the disease, and $28.1 \%$ of children had exacerbations observed after treatment, which were characterized by a lower intensity of clinical manifestations.

Conclusions. The introduction of a nonsteroidal activated zinc pyrithione drug $(0.2 \%$ cream or $0.2 \%$ aerosol) as topical monotherapy in the complex treatment of atopic dermatitis complicated by secondary fungal and bacterial infection showed high clinical efficacy.

Keywords: atopic dermatitis, children, secondary fungal and bacterial infection, topical therapy, activated pyrithione zinc

For citation: Malanicheva T.G., Ziatdinova N.V. Effectiveness of topical therapy of secondarily infected atopic dermatitis in children. Meditsinskiy Sovet. 2022;16(1):150-152. (In Russ.) https://doi.org/10.21518/2079-701X-2022-16-1-150-152.

Conflict of interest: the authors declare no conflict of interest.

\section{ВВЕДЕНИЕ}

Атопический дерматит (АД) занимает первое место в структуре аллергических заболеваний у детей, а его частота непрерывно увеличивается и составляет от 13 до 25\% [1-3]. В современных условиях атопический дерматит характеризуется ранним началом, упорным рецидивирующим течением, развитием осложнений и имеет определенные трудности в лечении [4, 5]. В настоящее время в условиях экологического неблагополучия, нерационального применения антибиотиков одними из факторов, приводящих к утяжелению АД, является бактериальная и грибковая инфекция, которая играет важную роль в поддержании хронического воспалительного процесса в коже. В последние годы особое внимание исследователей обращено на патогенетическое значение грибковой и микробной флоры кожи у пациентов с АД [6-10]. Исходя из вышеизложенного, целью исследований явилось совершенствование методов лечения АД у детей, осложненного грибковой и бактериальной инфекцией.

\section{МАТЕРИАЛЫ И МЕТОДЫ}

Обследовано 46 детей с АД, имеющих осложненное течение бактериальной и грибковой инфекций, в возрасте от 1 года до 3 лет. У всех пациентов отмечалось среднетяжелое течение заболевания. Проводились клиническое, специфическое аллергологическое (сбор аллергологического анамнеза, кожное тестирование, определение специфических $\mathrm{lgE}$ ), бактериологическое и микологическое обследования пораженных участков кожных покровов с выделением чистой культуры гриба. Уровень циркулирующего кандидозного антигена в сыворотке крови, представляющего собой маннопротеиновый антиген клеточной стенки Candida albicans, определяли методом амперометрического иммуноферментного сенсора с использованием поликлональной кроличьей сыворотки [11].

Анализ результатов культурального бактериологического обследования у 46 детей в возрасте от 1 до 3 лет с осложненными формами АД показал, что у 86,9\% больных с грибковой колонизацией кожи отмечалась ассоциация с бактериальной флорой - Staphylococcus aureus. Итак, наслоение грибковой инфекции при АД у детей, часто в ассоциации с бактериальной флорой, поддерживает хроническое воспаление в коже и способствует устойчивости к противоаллергической терапии. Исходя из этого, в состав комплексного лечения АД показано включение средств, оказывающих противогрибковое и противомикробное действие. К таким средствам для наружного применения относится нестероидный препарат Скин-кап, содержащий в качестве действующего вещества активированный пиритион цинк, который снижает внутриклеточный уровень АТФ, способствует деполяризации мембран клеток, вызывая гибель грибов, бактерий, а также вовлеченных в патологический процесс клеток, особенно находящихся в стадии пролиферации. Аэрозоль и крем Скин-кап оказывают противомикробное, противогрибковое, противовоспалительное действие. То есть имеются все показания для назначения данного препарата при осложненном течении АД грибковой и бактериальной инфекцией.

Препарат Скин-кап назначался в составе комплексной терапии АД (гипоаллергенная диета, антигистаминные препараты, сорбенты, лечебно-косметический уход за кожей). При осложненном инвазивной кандидозной инфекцией течении заболевания, подтвержденной наличием в сыворотке крови циркулирующего кандидозного антигена, - в комплексе с системными антимикотиками.

У детей раннего возраста назначался крем Скин-кап при лихеноидных и эритематозно-сквамозных формах, аэрозоль Скин-кап - при экссудативных формах АД. Препарат применяли на пораженные участки кожи два раза в день в течение 14-21 дня.

\section{РЕЗУЛЬТАТЫ И ОБСУЖДЕНИЕ}

Оценка эффективности применяемой терапии проводилась на основе общего терапевтического эффекта, снижения индекса SCORAD более чем в три раза, достижения периода ремиссии, снижения уровня сенсибилизации.

На фоне проводимой терапии отмечается положительный клинический эффект в 69,5\% случаев. С 4-го дня от начала лечения отмечалась выраженная положительная динамика со стороны кожного процесса - уменьшение площади поражения в 1,5-2 раза, уменьшение объективных симптомов на коже, а также снижение интенсивности зуда и улучшение сна. У 59,4\% больных к 14-му дню достиг- 
нута полная ремиссия заболевания, что характеризовалось исчезновением воспалительных элементов на коже: гиперемии, расчесов, высыпаний, шелушения и мокнутия. У части детей сохранялась только сухость кожи и лихенификация. У 40,6\% наблюдаемых детей отмечалось значительное улучшение со стороны кожного процесса. Средняя продолжительность обострения составила 16 дней, индекс SCORAD снизился в 3,2 раза - с 45 до 13 баллов.

Результаты культурального бактериологического и микологического обследования были отрицательными в 78,1\% случаев.

Динамическое наблюдение за детьми в течение 1 года показало, что у 53,1\% наблюдалась стойкая ремиссия заболевания и после отмены препарата не наблюдалось обострения дерматита, а у 28,1\% детей обострения, отмечаемые после проводимого лечения, характеризовались более низкой интенсивностью клинических проявлений со стороны кожного процесса, уменьшением зуда и площади высыпаний, интенсивности воспалительных проявлений. У 28,1\% детей при обострении АД по требованию назначались повторные курсы Скин-капа, что привело к ремиссии заболевания.

Переносимость препарата Скин-кап у детей раннего возраста с АД на протяжении всего курса лечения оценивалась как хорошая. Побочных эффектов зарегистрировано не было.

\section{Выводы}

Таким образом, включение в состав комплексного лечения АД, осложненного вторичной грибковой и бактериальной инфекцией, нестероидного препарата Скин-кап в варианте топической монотерапии показало высокую клиническую эффективность и может быть рекомендовано к практическому использованию.

Поступила / Received 28.12.2021

Поступила после рецензирования / Revised 13.01.2022

Принята в печать / Accepted 20.01.2022

- Список литературы / References

1. Weidinger S., Novak N. Atopic dermatitis. Lancet. 2016;387(10023):1109-1122 https://doi.org/10.1016/S0140-6736(15)00149-X

2. van de Veen W., Akdis M. Mechanisms of immune regulation in allergy. In: Akdis C.A., Agache I. EAACI Global Atlas of Allergy. Zurich: European Academy of Allergy and Clinical Immunology; 2014. 388 p. Available at: https://www.zora.uzh.ch/id/eprint/140934/1/GlobalAtlasAllergy.pdf.

3. Смирнова Г.И. Атопический дерматит у детей: новое в патогенезе, диагностике и лечении. Лечащий врач. 2017;(4):12-19. Режим доступа: https://www.lvrach.ru/2017/04/15436702.

Smirnova G.I. Atopic dermatitis in children: the new in pathogenesis, diagnostics and treatment. Lechaschi Vrach. 2017;(4):12-19. (In Russ.) Available at: https://www.lvrach.ru/2017/04/15436702.

4. Балаболкин И.И. (ред.). Лечение аллергических заболеваний у детей. М.: МИА; 2008. 352 c.

Balabolkin I.I. (ed.). Treatment of allergic diseases in children. Moscow: MIA; 2008. 352 p. (In Russ.)

5. Кубанов А.А., Намазова-Баранова Л.С., Хаитов Р.М., Ильина Н.И., Алексеева Е.А., Амбарчян Э.Т. и др. Атопический дермати: клинические рекомендации. М.: Оригинал макет; 2020.69 с. Режим доступа: https://raaci.ru/dat/pdf/KR/atopic_dermatitis_2020.pdf. Kubanov A.A., Namazova-Baranova L.S., Khaitov R.M., Il'ina N.I., Alekseeva E.A., Ambarchyan E.T. et al. Atopic dermatitis: clinical guidelines. Moscow: Original-Maket; 2020.69 p. (In Russ.) Available at: https://raaci. ru/dat/pdf/KR/atopic dermatitis 2020.pdf.

6. West C.E., Jenmalm M.C., Prescott S.L. The gut microbiota and its role in the development of allergic disease: a wider perspective. Clin Exp Allergy. 2015;45(1):43-53. https://doi.org/10.1111/cea.12332.

7. Penders J., Gerhold K., Stobberingh E.E., Thijs C., Zimmermann K., Lau S., Hamelmann E. Establishment of the intestinal microbiota and its role for atopic dermatitis in early childhood. J Allergy Clin Immunol. 2013;132(3):601-607. https://doi.org/10.1016/j.jaci.2013.05.043.
8. Ревякина В.А., Смирнова Г.И. Научно-практическая программа «Атопический дерматит и инфекции кожи у детей: диагностика лечения и профилактика. Вопросы современной педиатрии. 2004;3(1):30-32. https://www.elibrary.ru/item.asp?id=17921573.

Revyakina V.A., Smimova G.I. Scientific and practical program "Atopic dermatitis and skin infections in children: diagnosis, treatment and prevention". Current Pediatrics. 2004;3(1):30-32. (In Russ.) Available at: https://www.elibrary.ru/item.asp?id=17921573.

9. Маланичева Т.Г., Хаертдинова Л.А. Энтеросорбция в лечении детей, больных атопическим дерматитом, осложненным грибковой инфекцией. Лечащий врач. 2013;(6):66. Режим доступа: https://www. lvrach.ru/2013/06/15435738.

Malanicheva T.G., Haertdinova L.A. Entero-absorption in treatment of children suffering from atopic dermatitis, complicated by fungus infection. Lechaschi Vrach. 2013;(6):66. (In Russ.) Available at: https://www.lvrach. ru/2013/06/15435738.

10. Смирнова Г.И. Современные подходы к диагностике и лечению осложненных форм атопического дерматита у детей. Клиническая дерматология и венерология. 2008;(5):101-106.

Smirnova G.I. Advanced approaches to diagnosis and treatment of complicated forms of atopic dermatitis in children. Klinicheskaya Dermatologiya i Venerologiya. 2008;(5):101-106. (In Russ.)

11. Кутырева М.Н., Медянцева Э.П., Халдеева Е.В., Глушко Н.И., Будников Г.К. Определение антигена Candida albicans с помощью амперометрического иммуноферментного сенсора. Вопросы медицинской химии. 1998;44(2):172-178. Режим доступа: http://pbmc ibmc.msk.ru/en/article-en/PBMC-1998-44-2-172.

Kutyreva M.P., Medyantseva E.P., Khaldeeva E.V., Glushko N.I., Budnikov G.K. Determination of antigen Candida albicans with amperometric enzyme immunosensor. Voprosy Meditsinskoi Khimii. 1998;44(2):172-178. (In Russ.) Available at: http://pbmc.ibmc.msk.ru/en/article-en/PBMC-1998-44-2-172.

\section{Информация об авторах:}

Маланичева Татьяна Геннадьевна, д.м.н., профессор кафедры пропедевтики детских болезней и факультетской педиатрии, Казанский государственный медицинский университет; 420012, Россия, Казань, ул. Бутлерова, д. 49; tgmal@mail.ru

Зиатдинова Нелли Валентиновна, к.м.н., доцент кафедры пропедевтики детских болезней и факультетской педиатрии, Казанский государственный медицинский университет; 420012, Россия, Казань, ул. Бутлерова, д. 49; ziatdin@mail.ru

\section{Information about the authors:}

Tatyana G. Malanicheva, Dr. Sci. (Med.), Professor of the Department of Propaedeutics of Children's Diseases and Faculty Pediatrics, Kazan State Medical University; 49, Butlerov St., Kazan, 420012, Russia; tgmal@mail.ru

Nelli V.Ziatdinova, Cand. Sci. (Med.), Associate Professor of the Department of Propaedeutics of Children's Diseases and Faculty Pediatrics, Kazan State Medical University; 49, Butlerov St., Kazan, 420012, Russia; ziatdin@mail.ru 